\title{
Mobile Incubation in Waved Albatross (Phoebastria irrorata): Associated Hatching Failure and Artificial Mitigation
}

\section{Incubation mobile chez l'Albatros des Galapagos (Phoebastria irrorata): Échec correspondant de l'incubation et atténuation artificielle}

\author{
Jill A. Awkerman $^{1}, \underline{\text { Kathryn P. Huyvaert }}^{2}$, and $\underline{\text { David J. Anderson }}^{1}$
}

\begin{abstract}
Waved albatrosses often relocate their eggs during incubation by placing the egg between the tarsi and shuffling forward. This behavior frequently results in eggs becoming lodged between rocks, accounting for at least $10 \%$, and perhaps as much as $80 \%$, of breeding failures. Because albatross populations worldwide are currently threatened, artificial means of augmenting reproductive success may be necessary to mitigate losses caused by anthropogenic effects. We characterize the frequency and extent of egg movement; test several hypotheses related to microhabitat, timing, and incubation location to explain the behavior; and investigate the utility of repositioning lodged eggs in a location in which breeding birds might resume incubation. Egg rescue increased both the likelihood of continued incubation as well as the hatching rate in our experiment, and provides an efficient, low-cost management option for this species.

RÉSUMÉ. L'Albatros des Galapagos déplace souvent son oeuf pendant l'incubation en le plaçant entre les tarses et en traînant des pattes. Ce comportement a souvent comme conséquence de coincer l'oeuf entre les roches, ce qui expliquerait au moins $10 \%$, et peut-être jusqu'à $80 \%$, des échecs de reproduction. Puisque les populations d'albatros du monde sont présentement menacées, il serait peut-être nécessaire de recourir à des moyens artificiels pour augmenter les chances de reproduction réussie et réduire les pertes causées par des facteurs anthropiques. Nous décrivons la fréquence et la distance des déplacements, vérifions plusieurs hypothèses sur le microhabitat, le moment et le lieu d'incubation pour expliquer le comportement, et examinons l'utilité de déplacer les oeufs coincés là où des oiseaux nicheurs pourraient continuer l'incubation. La récupération des oeufs a augmenté les chances de continuer l'incubation et aussi d'améliorer le taux d'éclosion pendant notre expérience et elle est une façon efficace et peu coûteuse d'aider à rétablir l'espèce.
\end{abstract}

Key Words: egg movement; waved albatross; Pheobastria irrorata; reproductive success; egg adoption; management; egg incubation 


\section{INTRODUCTION}

Regular movement of waved albatross (Phoebastria irrorata) eggs by incubating adults represents an unusual aspect of their ecology as well as a unique opportunity for conservation management, because this behavior can lead to substantial breeding failure (Harris 1973). These ground-nesting seabirds frequently move their single-egg clutches around the breeding colony by shuffling forward with the egg between the tarsi and then resume incubation in the new location, sometimes several meters away (Harris 1973). Breeding adults are unable to continue incubating eggs that become lodged between rocks or under vegetation during egg movement. Waved albatross embryos are remarkably hardy without continuous incubation: eggs abandoned for up to six consecutive days hatched if incubation was resumed (Harris 1973), and live embryos were observed in eggs abandoned for up to 15 days (M. Westbrock, personal communication, unpublished data). Nonetheless, eggs that were misplaced between rocks and abandoned constituted $10 \%$ of failed breeding attempts in 1970 and 1971. Another $18 \%$ of failed eggs that were cracked might have also been rolled by an incubating bird and damaged against a rock. An additional 52\% of eggs disappeared because of movement to a new location or possibly depredation by mockingbirds (Nesomimus macdonaldi), so that egg movement could contribute to as much as $80 \%$ of all reproductive failures during incubation (Harris 1973). Identification of the causes of egg relocation may improve the efficiency of techniques to mitigate losses resulting from egg movement.

The root causes of egg movement are unknown and are of both scientific and management interest. Adopting a comparative approach, we note that waved albatrosses are different from other albatross species in several respects, including egg movement. They are the only species of tropical albatross, breeding on the equator, which prompts the functional hypothesis that egg movement is a response to local thermal stress. Waved albatrosses are also unusual in sharing Isla Española with giant tortoises (Geochelone elephantopus hoodensis). Although egg movement may be an adaptive response to the bulldozerlike approach of a tortoise (H. Snell, personal communication), it is common in the absence of tortoises, which were virtually extirpated from the island by the middle of the last century (de Vries 1984). Similarly, sea lions (Zalophus wollebaeki) occupy some of the coastal regions in which waved albatrosses nest and could disrupt fixed nest sites, although egg movement also occurs in areas without sea lions (Harris 1973). Eggs might be moved either to escape an unwanted neighbor or to join in colonial nesting, but this cause of movement should apply equally to other albatross species, none of which move their eggs. Finally, ectoparasites of waved albatrosses include soft ticks, lice, hippoboscid flies, and mosquitoes (Harris 1973, Anderson and Fortner 1986), and Vásquez (1981) suggested that incubators might move their eggs to avoid areas with tick-infested substrates. Again, ectoparasites are not unique to waved albatrosses.

In the face of the obvious risks to brittle eggshells from movement, most bird species establish a fixed nesting site or produce a conical egg shape that limits movement, and their eggs remain at one site throughout incubation. Woodpeckers and corvids occasionally carry or move their eggs, usually following disturbance at the original laying site (Truslow 1967, Blomme 1983, Trost and Webb 1986, Weaver and Brown 2004). Observation of egg movement by black vultures nesting in an abandoned building was documented by Stewart (1974). In contrast to albatross species that build large nest cups to contain the stationary egg, waved albatross nests vary from nest scrapes on dirt and pebbles to minimal accumulations of dirt, feathers, vegetation, or pebbles that do not confine the egg. The resulting mobility of the egg could facilitate an egg-dumping strategy. Wood ducks and other brood parasites "dump" eggs in host nests, but generally not by moving an egg that has already been laid (cf. Brown and Brown 1996, Ryan et al. 1998). Egg dumping by species with multiple egg clutches capitalizes on the possible misidentification of eggs by the host to increase reproductive output with minimal effort. Confusion of eggs is less likely for single egg clutches, but plausible in the case of waved albatrosses, which move their eggs frequently. An alternative benefit related to, but distinct from, egg dumping could accrue to egg movers if movement placed eggs near potential adopters. Abandoned eggs are occasionally incubated by nonbreeders or failed breeders (J. A. Awkerman and K. P. Huyvaert, personal observation).

Egg movement could also be a maladaptive product of inexperience in young birds or of poor 
coordination between mates. Wandering albatrosses (Diomedea exulans) commonly change nest sites between years, and occasionally mates select different nest sites and one of them does not incubate, causing breeding failure (Tickell 2000). Egg movement in waved albatrosses may be the result of similar poor coordination in nest site selection within a breeding pair. Primiparous waved albatross females lay longer, narrower eggs than other females do (Harris 1973, Rechten 1986, Tickell 2000), and an association of egg narrowness and movement would suggest an age effect of the female on the probability or distance of egg movement.

Management strategies to increase the reproductive success of bird species frequently include indirect means intended to improve the likelihood of successful breeding attempts, such as predator control (Donald et al. 2002, Moorhouse et al. 2003), habitat modification (Van Dyke et al. 2004), the installation of artificial nest sites (Bolton et al. 2004, Maicas and Haeger 2004), or even the relocation of breeding colonies (Kress and Nettleship 1988). Augmenting resource availability for adults early in the reproductive attempt or for chicks during rearing can directly affect reproductive efforts (Clifford and Anderson 2001, Gill and Hatch 2002). Captive breeding or artificial incubation can also increase reproductive output (Rahbek 1993, Meretsky et al. 2000, Brightsmith et al. 2005). In contrast, waved albatrosses present an unusual opportunity to augment reproduction within the breeding colony directly by improving parental access to misplaced eggs. We explore the usefulness of increasing the hatching success of this seabird, which is listed as a vulnerable species by the International Union for the Conservation of Nature and Natural Resources and currently experiencing unsustainable mortality of adults in fisheries operations (J. A. Awkerman, J. Mangel, J. A. Shigueto, K. P. Huyvaert, and D. J. Anderson, unpublished manuscript). If successful, egg rescue could be used to counter this anthropogenic effect on population size.

Although egg movement might appear to reduce reproductive success, Vásquez (1981) found a positive correlation between hatching success and frequency of movement. A principal objective of this study is to reevaluate this association. We also test several functional and ultimate-level hypotheses to explain the existence of the behavior. Finally, we compare the hatching success of parents whose inaccessible egg was experimentally "rescued" to that of controls.

\section{METHODS}

\section{Egg movement}

Virtually all waved albatrosses breed on Isla Española, Galápagos (Anderson et al. 2003). Our study site is located on the southeastern point of Isla Española at Punta Cevallos ( $\left.1^{\circ} 23^{\prime} \mathrm{S}, 89^{\circ} 37^{\prime} \mathrm{W}\right)$. We monitored egg movement and its correlates during three different breeding seasons (1996, 2002, and 2003), tracking eggs by daily monitoring with a flagged rock maintained $1 \mathrm{~m}$ north of the egg as it moved. The egg number was also written on the egg to avoid possible confusion during movement. Adult attendance at each nest was recorded daily in four years (1996, 2002, 2003, and 2004). In 1996, 75 nests were monitored daily, and the distance and direction of any movement $>0.2 \mathrm{~m}$ during the previous $24 \mathrm{~h}$ were recorded. An additional $11 \mathrm{eggs}$ were checked in both early to mid-morning and late afternoon, and the distance and direction from the closest shade vegetation were measured for $50 \mathrm{~d}$ to test one aspect of the microhabitat hypothesis. In 2002, we monitored 274 nests and noted the frequency of movements $>0.2 \mathrm{~m}$; we also recorded egg length and maximum breadth, which was used as a proxy for the previous breeding experience of the female. In 2003, we monitored 104 eggs for 30 $\mathrm{d}$ (17 May-15 June) and calculated average distance moved per daily age of egg. Ninety percent of all eggs were laid between 16 April and 19 May, and the mean incubation period is $65 \mathrm{~d}$ (J.A. Awkerman, unpublished data), so all egg ages were represented in this sample. Each day observers recorded which parent was incubating, the distance of the nest from the coastline, the distance to the nearest nesting neighbor of the incubating bird, the number of conspecifics within $2 \mathrm{~m}$, and the distance and direction of any movement $>0.5 \mathrm{~m}$ during the previous $24 \mathrm{~h}$. These data were used to examine movement in relation to location and density. In 2003, shaded air temperature was measured at $6 \mathrm{~min}$ intervals throughout the incubation period by a StowAway TidbiT temperature datalogger (Onset Computer Corporation, Bourne, Massachusetts, USA) with an effective range of $-20^{\circ} \mathrm{C}$ to $+50^{\circ} \mathrm{C}$. Temperature data provided another variable used to test the microhabitat hypothesis. 
In preliminary analyses to examine patterns of egg movement throughout incubation, we grouped data from eggs that were attended for at least $60 \mathrm{~d}$ into six $10 \mathrm{~d}$ intervals covering almost all of the $65 \mathrm{~d}$ incubation period. To determine whether movement varied with egg age and thus whether egg age should be considered in subsequent analyses, we categorized frequency and distance data from 1996 and frequency data only from 2002 into $10 \mathrm{~d}$ intervals. We used a repeated measures ANOVA with a year effect to compare proportions of movement frequency in each $10 \mathrm{~d}$ period relative to total movement by each bird. Following Zar (1996), arcsin transformation of proportions was not warranted. Adjustments to degrees of freedom were made upon violation of Mauchly's test of sphericity. The results of this test along with corrected results using the Greenhouse-Geisser epsilon are reported for cases in which the sphericity assumption was violated. A separate repeated measures ANOVA determined whether the distance moved in 1996 varied across intervals. We did not combine the distance data from 1996 and 2003 because the data from 2003 were based on partial incubation periods with incomplete temporal overlap, precluding a repeated measures approach. We used only eggs that were incubated until at least age $60 \mathrm{~d}$ to exclude behavior associated with egg hatching and to restrict data collection to the typical incubation period, excluding four eggs with incomplete data and leaving 60 eggs from 1996 and 125 eggs from 2002 in the analyses.

\section{Egg rescue experiment}

In 2004, eggs that had been abandoned since the previous day's nest check and were also inaccessible for incubation were randomly assigned to control or rescue treatments the first time the egg was found abandoned. In three cases, experimental eggs had to be rescued again on a second occasion. Control eggs were left in place and monitored as usual. Rescued eggs were moved far enough to place them in an area that was more accessible to the parent, on flat ground and approximately $0.2 \mathrm{~m}$ from rocks or other objects that might hinder incubation by the adult. The egg was moved the smallest possible distance from its site of abandonment to the nearest accessible area (approximately $0.5 \mathrm{~m}$ ). Daily nest monitoring continued as usual, and we identified any bird seen incubating an abandoned egg. The probability that incubation was resumed by banded parents was compared between control and rescued eggs. Egg movement prior to abandonment that did not leave the egg inaccessible or that resulted in cracking of the egg was known to occur but was not systematically monitored.

\section{Statistical analyses}

Statistical tests were performed with versions 5.5 and 6.0 of Statistica (Statsoft, Tulsa, Oklahoma, USA) and version 12 of SPSS (SPSS, Chicago, Illinois, USA). We used logistic regression to test associations between continuous independent variables and the binary dependent variable hatching success. $G$-tests compared the probabilities of both control and experimental parents resuming incubation and, separately, hatching their eggs. Generalized Linear Models determined the relationship of several continuous variables with movement distance or frequencies. Nonparametric statistics were used when assumptions of normality were violated. When a given nest provided a single data value that was a mean of repeated measurements at that nest, we report standard error values for means calculated across nests (means of means; Zar 1996). We used ArcView GIS v. 3.2 (Environmental Systems Research Institute, Redlands, California, USA) to calculate the distances that a bird's nest site moved between 2002, 2003, and 2004 and to estimate the distance of each nest site from the nearest part of the coast.

\section{RESULTS}

\section{General characteristics of movement}

The 60 eggs that were incubated for at least $60 \mathrm{~d}$ in 1996 were moved a total average of $3.9 \mathrm{~m}$ (SD = 5.9 , median $=2.1$, range $=0.0-36.1$ ) on an average of $7.6 \mathrm{~d}(\mathrm{SD}=6.1$, median $=6$, range $=0-29)$. The location of all 75 eggs either on day 60 or at nest failure was on average $1.2 \mathrm{~m}(\mathrm{SD}=1.9$, median $=$ 0.6 , range $=0.0-13.4$ ) from its original location at laying. For the subset of nests that were active for at least $60 \mathrm{~d}$, the egg's final location was also $1.2 \mathrm{~m}$ from the original location $(\mathrm{SD}=2.1$, median $=0.5$, range $=0.0-13.4)$. Only four of the eggs $(6.7 \%)$ were not moved at least $0.2 \mathrm{~m}$ from the laying location during the first $60 \mathrm{~d}$ of incubation in 1996. The 125 eggs that were incubated at least $60 \mathrm{~d}$ in 2002 were moved on an average of $9.0 \mathrm{~d}(\mathrm{SD}=6.9$, median $=9)$. Nine of these eggs $(7.2 \%)$ were not 
moved from the laying location during the first 60 $\mathrm{d}$ of incubation. During the $30 \mathrm{~d}$ monitoring period in 2003, eggs were moved on average $3.1 \mathrm{~m}$ (SD = 4.6 , median $=1.5$, range $=0-26.9$ ) from the location at laying. Movements sometimes resulted in extensive straight-line displacements from the original point of laying, but often did not (Fig. 1). The duration of an individual parent's incubation stint, i.e., number of consecutive days on nest, was not significantly correlated with distance of egg movement during that stint (Spearman $r=0.12, n=$ $182, P=0.10)$.

Repeated measures ANOVA of movement probability across $10 \mathrm{~d}$ age classes revealed an interaction between egg age and year $\left(F_{5.815}=3.32\right.$, $P=0.06$; Fig. 2A). Movement probability did not differ across age classes in $2002\left(F_{5,575}=8.75, P=\right.$ 0.50 ), but it did in 1996 (Mauchly's $W=0.49, \chi^{2}=$ $33.17, P=0.003 ; F_{3.90,186.94}=3.41, P=0.011$; see Methods for correction of violation of sphericity assumption).

Total distance moved per interval did not vary across interval in 1996 (repeated measures ANOVA, $F_{5,260}=1.01, P=0.41$; Fig 2B). Visual inspection of the 2003 data suggested an increase in distance moved in the final $10 \mathrm{~d}$ period (Fig. 2B). Using a $30 \mathrm{~d}$ window of observation in 2003 could have confounded the effects of age class with those of lay date, but apparently did not: mean distance of egg movement over the $30 \mathrm{~d}$ period was not correlated with lay date (Spearman $r=0.01, n=$ $153, P=0.86)$. Based on these results, the analyses below of egg movement frequency combine all age classes for 2002 and exclude the last age class for 1996. Likewise, the analyses below of egg movement distance combine all age classes for 1996 and exclude the last age class for 2003.

The number of days in which movement occurred was strongly correlated with the total distance moved in 1996 (first 50 d only; Spearman $r=0.93$, $n=61, P<10^{-5}$ ) and 2003 (first 50 d only; Spearman $\left.r=0.98, n=103, P<10^{-3}\right)$; these two variables thus appear to reflect the same underlying tendency of an egg's parents to move it.

\section{Movement and hatching success}

We compared hatching success with the proportion of the total incubation days during which the egg was moved (proportion of days moved) in each of the years 1996, 2002, and 2003, using only the first $50 \mathrm{~d}$ of incubation in 1996 and in 2003. Logistic regression showed that frequency of movement per day of incubation was a significant predictor of hatching success in $2003\left(\chi^{2}=25.80, P<10^{-7}\right.$; Fig. $3 C)$ and approached significance in $1996\left(\chi^{2}=3.21\right.$, $P=0.07$; Fig. $3 \mathrm{~A})$ and in $2002\left(\chi^{2}=3.18, P=0.07\right.$; Fig. 3B). Eggs that hatched had a lower frequency of movement $($ mean $=0.08, \mathrm{SD}=0.11$, median $=$ 0.03 ) than did failed eggs in 2003 (mean $=0.25, \mathrm{SD}$ $=0.26$, mean $=0.14)$. Greater mean distances of movement in 2003 are due to the more conservative criterion of movement $(>0.5 \mathrm{~m})$ than the $0.2 \mathrm{~m}$ threshold used in both 1996 and 2002.

For a complementary analysis, logistic regression showed that distance moved per day of incubation was a significant predictor of hatching in $1996\left(\chi^{2}=\right.$ 8.12, $P=0.004$; Fig. 4A), with eggs that failed having been moved greater distances (mean $=0.17$ $\mathrm{m}, \mathrm{SD}=0.35$, median $=0.04)$ than eggs that hatched (mean $=0.05 \mathrm{~m}, \mathrm{SD}=0.06$, median $=0.03$ ). Mean daily movement distance during the $30 \mathrm{~d}$ observation period in 2003 was also a significant predictor of hatching success (logistic regression, $\chi^{2}=13.31, P<10^{-4}$; Fig. 4B), with eggs that failed having been moved greater distances (mean $=1.58$ $\mathrm{m}, \mathrm{SD}=1.42$, median $=1.44$ ) than eggs that hatched $($ mean $=0.86 \mathrm{~m}, \mathrm{SD}=0.97$, median $=0.88)$.

A multivariate logistic regression showed that both distance from the coast at laying and average daily distance moved were significant predictors of hatching success in 2003, with distance from the coast at laying accounting for $33.1 \%$ of the variance in hatching success (Wald statistic $=8.2, P=0.004$ ) and average movement distance accounting for an additional $7.4 \%$ (Wald statistic $=4.8, P=0.029$ ). A further univariate analysis showed distance from coast at laying to be a strong predictor of hatching success in $2003\left(\chi^{2}=29.5, P=10^{-7}\right.$, Fig. 5).

\section{Vegetation and temperature}

In 1996, the mean distance of movements toward the nearest vegetation $(0.8 \mathrm{~m}, \mathrm{SD}=0.4)$ was no different from those away from vegetation $(1.0 \mathrm{~m}$, $\mathrm{SD}=0.8$; paired $t$-test, $t=0.74, \mathrm{df}=11, P=0.47$ ). In addition, the mean number of movements toward vegetation $(5.6, \mathrm{SD}=3.3)$ did not differ from the number away from vegetation $(5.3, \mathrm{SD}=3.1$; paired $t$-test, $t=0.58, \mathrm{df}=11, P=0.57)$. Movements were noted more often during the morning check (5.2 
Fig. 1. Tracks of extensive egg movement at 10 selected nests in 2003. Each color indicates the path of an individual egg. Origin of graph $(0,0)$ indicates laying location of each egg.

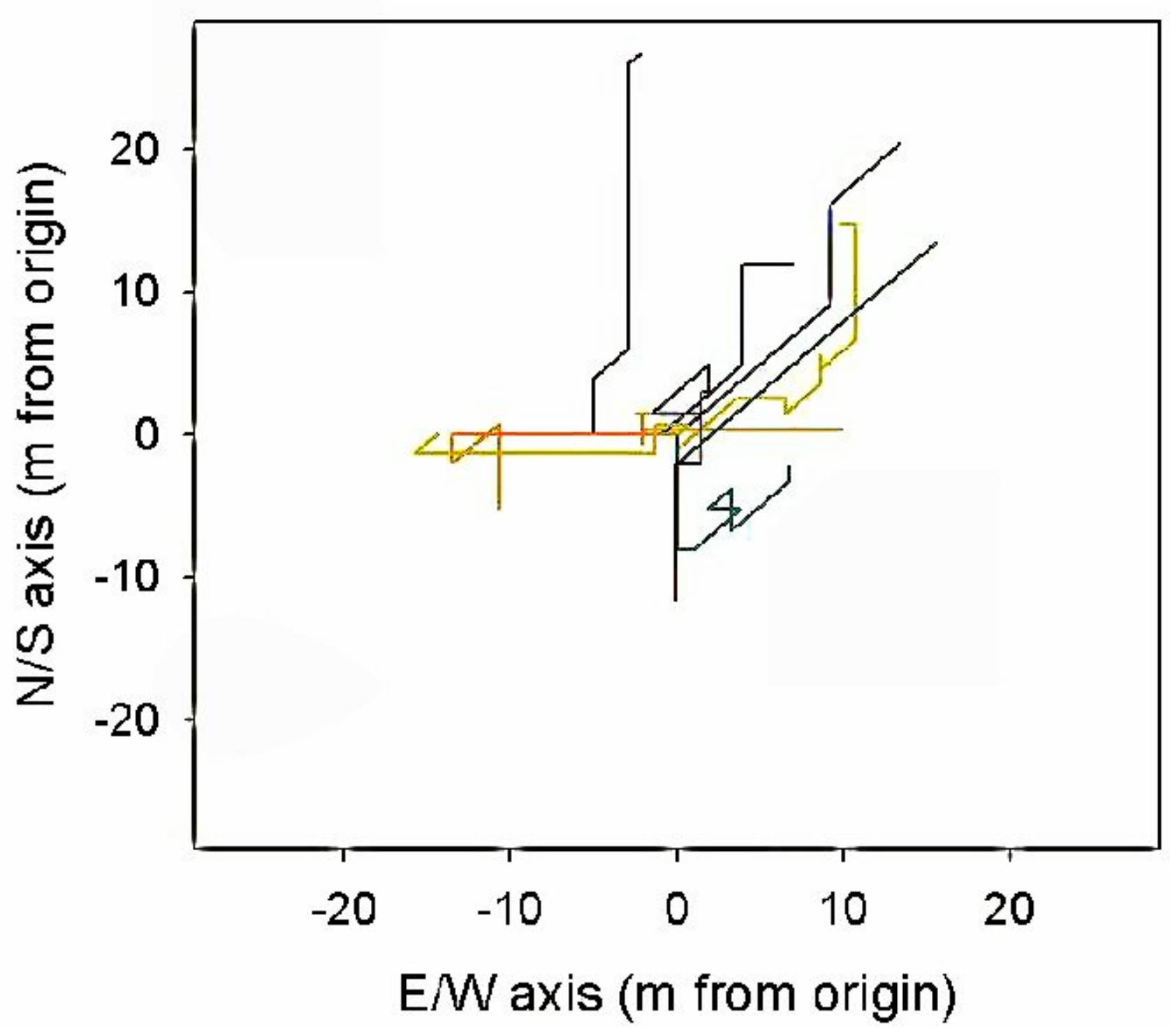

moves, $\mathrm{SE}=1.0)$ than the afternoon check $(3.3$ moves, $\mathrm{SE}=0.7$; paired $t$-test, $t=2.92, \mathrm{df}=19, P$ $=0.009$ ), indicating more movement in the cooler hours of nighttime and early morning than during the hotter midday hours. Testing the hypothesis that higher temperatures may cause increased movement, a General Linear Model analysis showed that daily temperature declined significantly during the $30 \mathrm{~d}$ monitoring period in 2003 (adjusted $\left.R^{2}=0.22, F_{(1,28)}=9.39, P=0.005\right)$, and movement declined over this period as well, although the daily high temperature was not correlated with the daily 
Fig. 2. (A) Proportion of movement per $10 \mathrm{~d}$ intervals for eggs that were moved and incubated at least 60 $\mathrm{d}$ in $1996(n=49)$ and $2002(n=116)$. (B) Average distance eggs were moved per $10 \mathrm{~d}$ interval $1996(n=$ $56)$ and $2003(n=153)$ for eggs that were incubated for at least $60 \mathrm{~d}$ in $1996(n=56)$ and throughout the $30 \mathrm{~d}$ monitoring period in $2003(n=153)$.

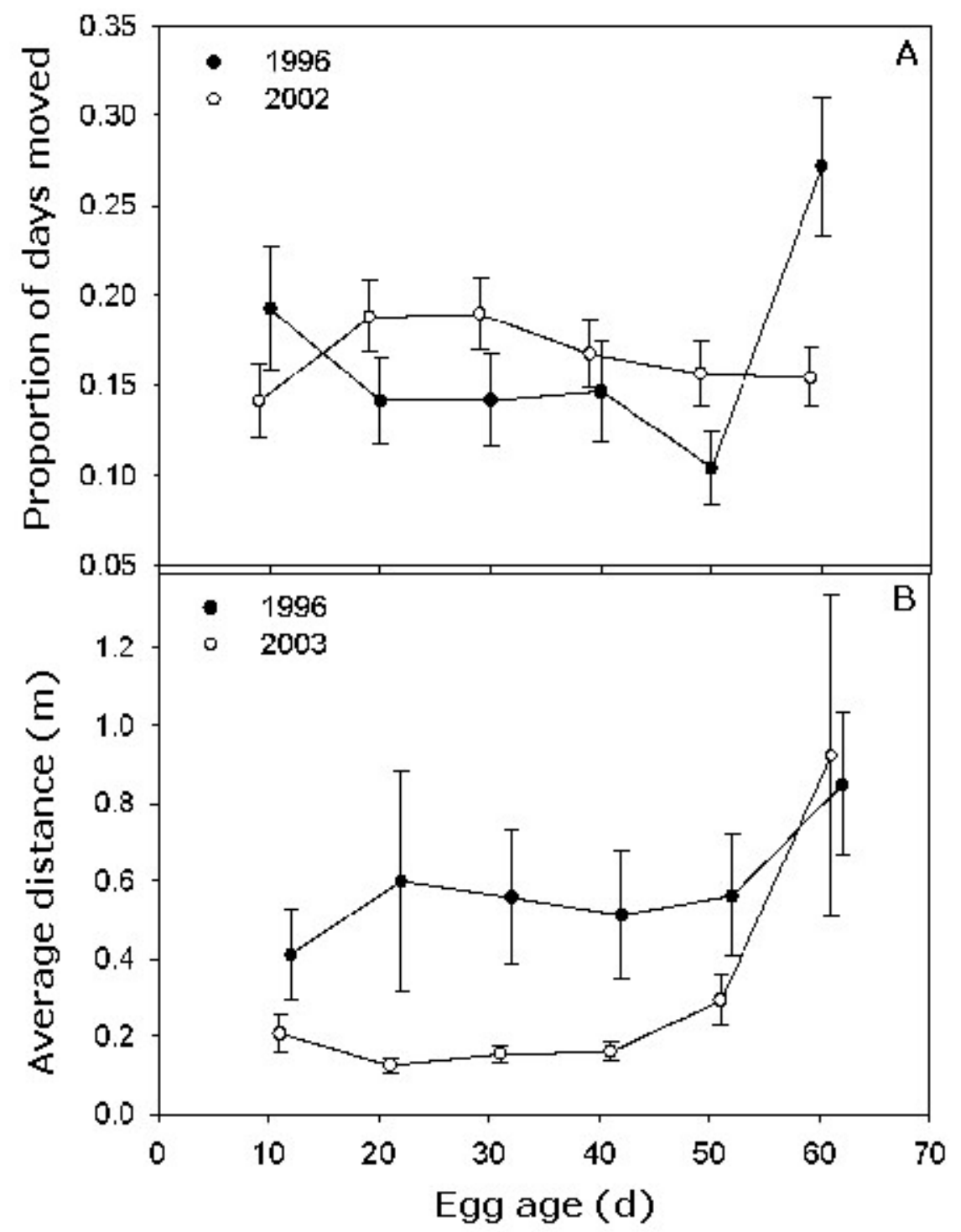


Fig. 3. Logistic regression of hatching fate on proportion of days with movement for 75 nests in 1996, 274 nests in 2002, and 153 nests in 2003. Vertical bars indicate number of points falling in each proportion interval (width $=0.025)$.

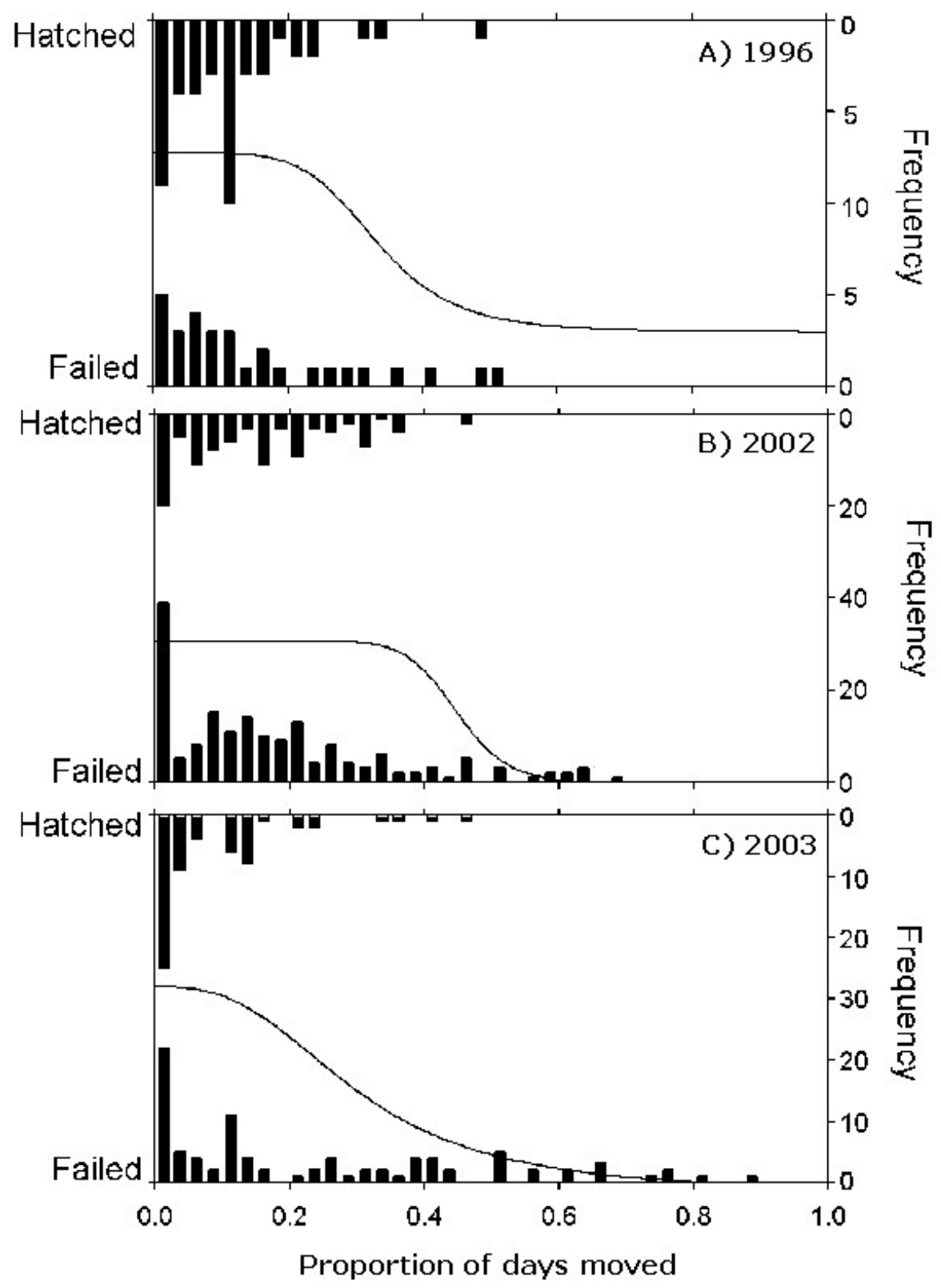


Fig. 4. Logistic regression of hatching fate on distance of average daily movement for 75 nests in 1996 and 153 nests in 2003.

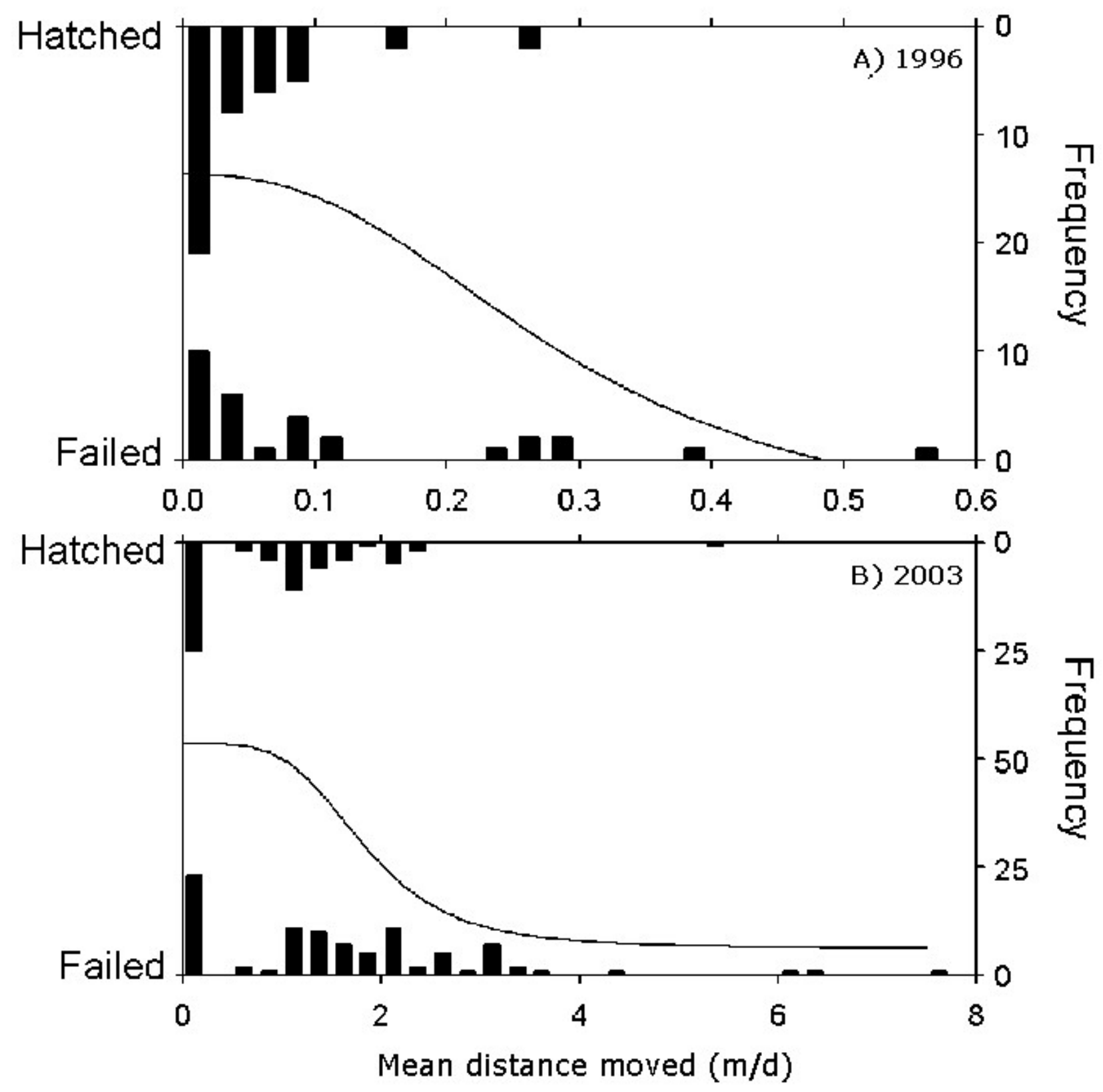


Fig. 5. Distance from coast at laying, identified as a predictor of hatching success for 153 nests in 2003 in a multivariate logistic regression.

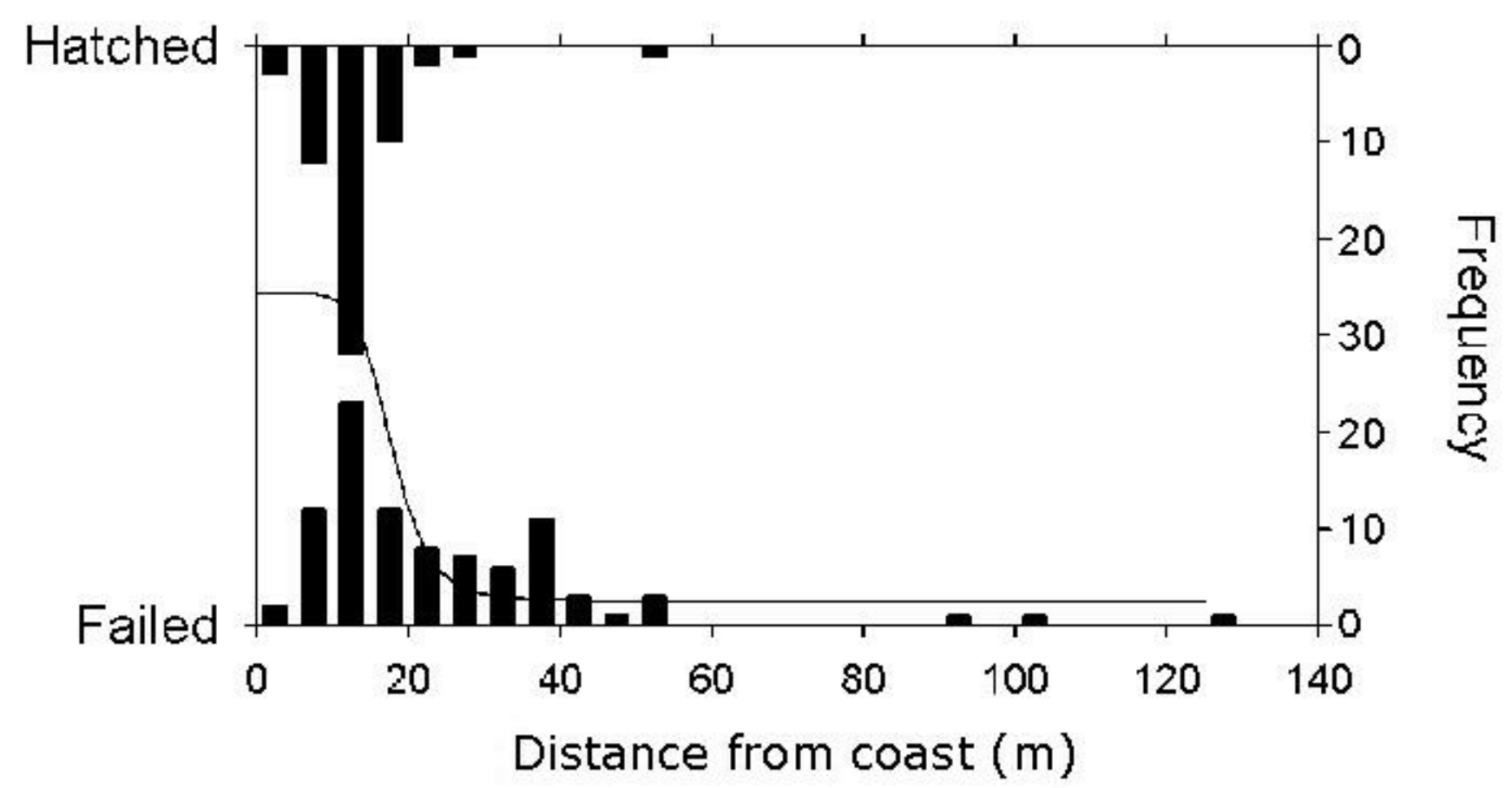

average distance moved by all monitored birds $\left(\right.$ adjusted $\left.R^{2}=-0.014, F_{(1,28)}=0.58, P=0.45\right)$.

\section{Location and nest density}

In 2003, an egg's distance to the coast at laying was strongly correlated with its mean daily distance moved during the first $50 \mathrm{~d}$ of incubation (Spearman $r=0.49, n=154, P<10^{-6}$, Fig. 6A), and with the net change in the egg's final distance from the coast (Spearman $r=-0.16, n=152, P=0.05$; Fig. 6B). The average daily distance moved was also positively correlated with average distance to nearest neighboring nest (Spearman $r=0.45, n=$ $153, P<10^{-6}$ ) and was negatively correlated with average albatross density within $2 \mathrm{~m}$ of the nest (Spearman $r=-0.36, n=154, P<10^{-6}$ ). Because distance to the coast was correlated with average distance to nearest neighbor (Spearman $r=0.28, n$ $=153, P<10^{-3}$ ), and marginally correlated with albatross density (Spearman $r=-0.14, n=153, P=$ 0.088 ), these results indicate that more movement occurred in sparsely populated inland areas. Correlations of distance moved with density variables were still significant when partial correlations were calculated, removing the effects of distance to coast (nearest neighbor: Spearman $r$ $=0.30, n=154, P<0.001$; density of albatrosses within 2 m: Spearman $r=-0.37, n=154, P<0.001)$.

Mean daily distance moved during the first $50 \mathrm{~d}$ of incubation in 2003 was significantly correlated with the distances between the 2002 and 2003 laying sites (Spearman $r=0.36, n=103, P<10^{-4}$ ), and between the 2003 and 2004 sites (Spearman $r=0.51, n=$ $116, P<10^{-6}$ ), suggesting that the birds that move their eggs farther during a given incubation period also move their laying sites interannually. Movement frequency during the first $50 \mathrm{~d}$ of incubation in 2003 was also significantly correlated with laying site movement between 2002 and 2003 
Fig. 6. Distance from coast at laying for 153 nests in 2003 with average daily distance moved (A) and movement relative to coastline (B) during $30 \mathrm{~d}$ of nest monitoring.

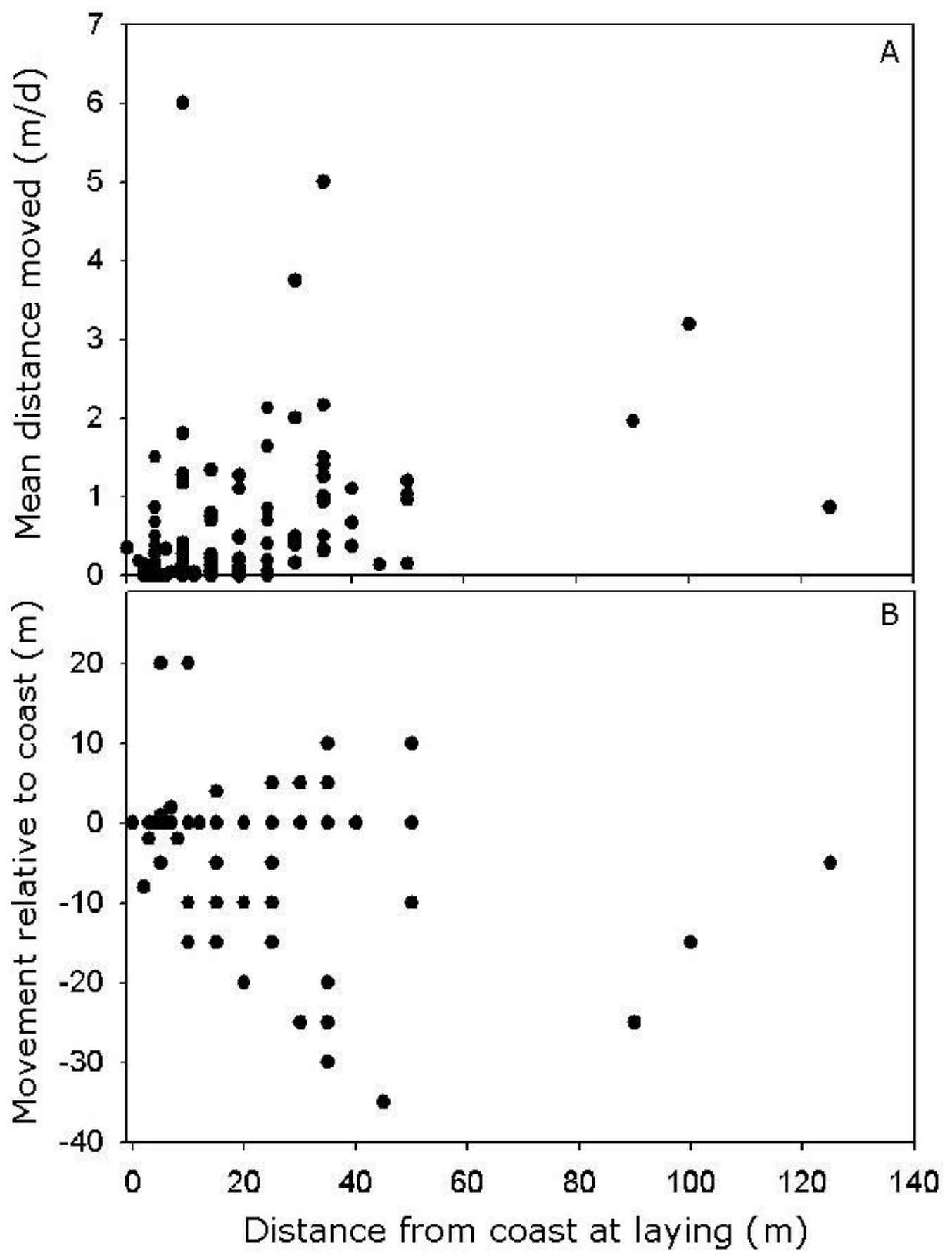


(Spearman $r=0.25, n=103, P=0.01$ ), and between 2003 and 2004 (Spearman $r=0.45, n=116, P<$ $10^{-7}$ ), but not between 2002 and 2004 (Spearman $r$ $=0.08, n=73, P=0.50)$.

Distance of laying site from the coast in 2003 showed a suggestive correlation with distance of laying site movement between 2002 and 2003 (Spearman $r=0.27, n=103, P=0.07$ ), and significant correlations with site movement between 2003 and 2004 (Spearman $r=0.23, n=$ 116, $P=0.01$ ) and between 2002 and 2004 (Spearman $r=0.28, n=73, P=0.02$ ). Distance of laying site from the coast in 2002 was correlated with the distance that the laying site was moved toward the coast in 2003 (Spearman $r=0.64, n=$ $116, P<10^{-6}$ ) and in 2004 (Spearman $r=0.69, n=$ $\left.120, P<10^{-6}\right)$, indicating that birds laying far from the coast moved their laying sites closer to the coast in subsequent years. However, distance from coast at laying in 2002 was not correlated with the distance that the laying site moved between 2002 and 2003 (Spearman $r=0.04, n=105, P=0.65$ ).

\section{Adoption of eggs}

Because egg movement within an incubation period and laying site relocation between years both tended to place eggs closer to conspecifics, both kinds of movement might represent adaptations to facilitate the temporary adoption of an egg. If so, then indicators of proximity to potential adopters should predict the probability that an abandoned egg would be adopted, but neither albatross density within $2 \mathrm{~m}$ nor distance to the nearest neighboring nest were proven to be predictors of adoption (logistic regressions, albatross density: $\chi^{2}=0.24, P=0.62$; distance to nearest nest: $\chi^{2}=2.5, P=0.11$ ).

In 2004, 7.0\% (64) of all monitored eggs were incubated on at least one occasion by a "foreign" adult, i.e., an adult previously seen incubating at another nest (67.2\% of cases) or a nonbreeding adult in addition to the two original breeders. Most of these "adoptions" were temporary: many $(37 \%)$ adoptive adults incubated for only one day before they themselves abandoned the egg, and $17.7 \%$ of adopted eggs were subsequently incubated again by at least one of the original parents. The most likely benefit that adoption could provide was "babysitting" in the absence of the biological parents, because in only two cases (3.2\% of adopted eggs) did the adoptive adults, not the original parents, eventually hatch the egg and feed the chick. Of all the eggs adopted for at least one day, $17.7 \%$ hatched.

Considering all the eggs abandoned and later recovered by the biological parents in 2004, the total number of days an egg was unincubated was a good predictor of hatching success (logistic regression, $\chi^{2}=25.8, P<10^{-6}$ ), with low attendance leading to low hatching success. Given that nonincubating waved albatrosses apparently have a tendency to babysit eggs, egg movement could be an adaptation to facilitate adoption by placing the egg closer to high-density nesting areas near potential babysitters and minimizing the time to adoption. However, the eggs that were adopted during the known absence of the biological parents (52 of 363) did not have significantly higher hatching success $(5.7 \%)$ than did those that were not attended by babysitters (311 of 363; hatching rate $=4.8 \% ; G=0.078, P>0.75$ ). Adopted eggs that hatched (11 eggs; $17.2 \%$ of all adopted eggs) constituted $1.2 \%$ of all 886 nesting attempts in 2004, and $2.8 \%$ of the 395 eggs that hatched in that year.

Our results suggest that eggs are moved farther in the sparsely populated inland areas in which breeding attempts are rarely successful, and that movement is generally toward the coast. Birds that are on the verge of abandoning their reproductive attempt might move their eggs to more densely populated areas to increase the likelihood that a babysitter may adopt the egg for a short period, possibly bridging a gap in the parent's absence and increasing the potential hatching success. Because proportion of days moved is correlated with density of albatrosses in the vicinity of the nest, we used the residuals of this relationship to determine whether movement of eggs by abandoning parents made their eggs more likely to be adopted. In 2003, residuals of proportion of days moved and albatross density within $2 \mathrm{~m}$ of the nest were not significant predictors of adoption among abandoned eggs (logistic regression, $\chi^{2}=0.24, P<0.62$ ). In a similar analysis, the residuals of movement frequency regressed on distance from coast were not significant predictors of adoption among all abandoned eggs (logistic regression, $\chi^{2}=0.15, P<$ $0.70)$. 


\section{Previous breeder experience}

In 2002, egg narrowness, i.e., ratio of breadth to length, was not significantly correlated with the probability that a female would move her egg relative to the number of days the egg was incubated (Spearman $r=-0.09, n=119, P=0.34$ ). Ratio of breadth to length was significantly correlated with both the number of days that a female incubated (Spearman $r=0.18, n=118, P=0.05$ ) and the total number of days that the egg was incubated by the pair (Spearman $r=0.22, n=123, P=0.01$ ), suggesting that females producing rounder eggs, or females with more breeding experience, tend to have nests that are active longer. Egg shape did not predict hatching success (logistic regression, $\chi^{2}=$ $2.55, P=0.11)$ and was not correlated with distance from coast (Spearman $r=-0.12, n=124, P=0.17$ ).

\section{Egg rescue experiment}

Abandonment because of egg movement to an inaccessible location occurred in $14.9 \%$ of nests in 2004. A total of 132 eggs that had been moved to inaccessible locations were randomly divided into 66 control eggs and 66 rescued eggs within $24 \mathrm{~h}$ of becoming inaccessible and abandoned. Breeding adults that abandoned lodged eggs were more than twice as likely to resume incubation of rescued eggs (39 of 66) than control eggs (16 of 66; $G=16.90$, df $=1, P<0.001$; Fig. 7$)$, and more chicks hatched from rescued eggs ( 10 of 66) than from control eggs (2 of 66; $G=6.36$, df $=1, P<0.025$ ). Statistical comparison of fledging success was precluded by small sample sizes: three of the 10 chicks from rescued eggs fledged, and neither of the two control chicks fledged. Only three of the 39 rescues in which incubation was resumed $(7.7 \%)$ required an additional rescue, suggesting that birds that resumed incubation were not likely to misplace their eggs again.

\section{DISCUSSION}

Egg movement and subsequent loss, breakage, or disappearance accounts for a large portion of reproductive failure in waved albatross. Harris (1973) found that egg movement was responsible for at least $10 \%$ of the breeding failure in 1970 and 1971 and may have preceded the breaking or disappearance of eggs, accounting for as much as $80 \%$ of all failure in those years. Nearly all birds move their eggs to some degree, suggesting that moderate amounts of movement may be tolerated. Contrary to the conclusion of Vásquez (1981), we found a negative association between movement frequency and hatching success in each of the three years studied.

Given this result, an adaptive explanation for egg movement requires that the parents that moved the most would have had even lower reproductive success than if they had failed to move. If, by moving their eggs toward densely populated areas, parents increase the chance of hatching by placing their eggs closer to potential incubators, facilitating temporary adoption, then the cost of increased likelihood of failure through egg moving may be worth the risk for parents that are preparing to abandon their eggs. Under this scenario, parents that abandon the reproductive attempt are in poorer condition than those that incubate their eggs to hatching. At present, we cannot make the assessment of parental quality required to test the hypothesis that birds expected to abandon their eggs will move them more frequently and increase the likelihood of having them adopted, and so we cannot definitively reject this adoption hypothesis as a factor favoring egg movement. The surprising discovery of adoptive behavior by foreign birds may be related to the presumed high philopatry of waved albatrosses, based on documented philopatry in other albatross species (Tickell 2000), placing relatives in close proximity. The presumably low cost for the adopter or babysitter of sitting on a nearby egg that has been abandoned, perhaps temporarily, could be balanced by potential fitness benefits if the egg belongs to a close relative. Data from microsatellite analyses fail to indicate the genetic substructure required under this idea (Huyvaert 2004). Moreover, when bandsharing values were examined, dyads of males, the more philopatric sex in most birds (Greenwood and Harvey 1982), nesting close together $(<40 \mathrm{~m}$, the maximum documented distance of egg movement) were not more closely related than males nesting farther apart ( $>40 \mathrm{~m}$; Mann-Whitney $U=219, Z=$ $0.539, P=0.59$; K. P. Huyvaert and G. P. Parker, unpublished data).

Our results showed that incubating birds nesting far from the coast tended to move their eggs farther and more frequently than did birds close to the coast, and that they oriented movement toward the coast, especially if their egg-laying site was sparsely populated. Although we found no evidence that microhabitat differences in shade or temperature 
Fig. 7. Proportion of both control and rescued eggs $(n=132)$ with resumed incubation by a parent following abandonment and proportion of eggs that hatched.

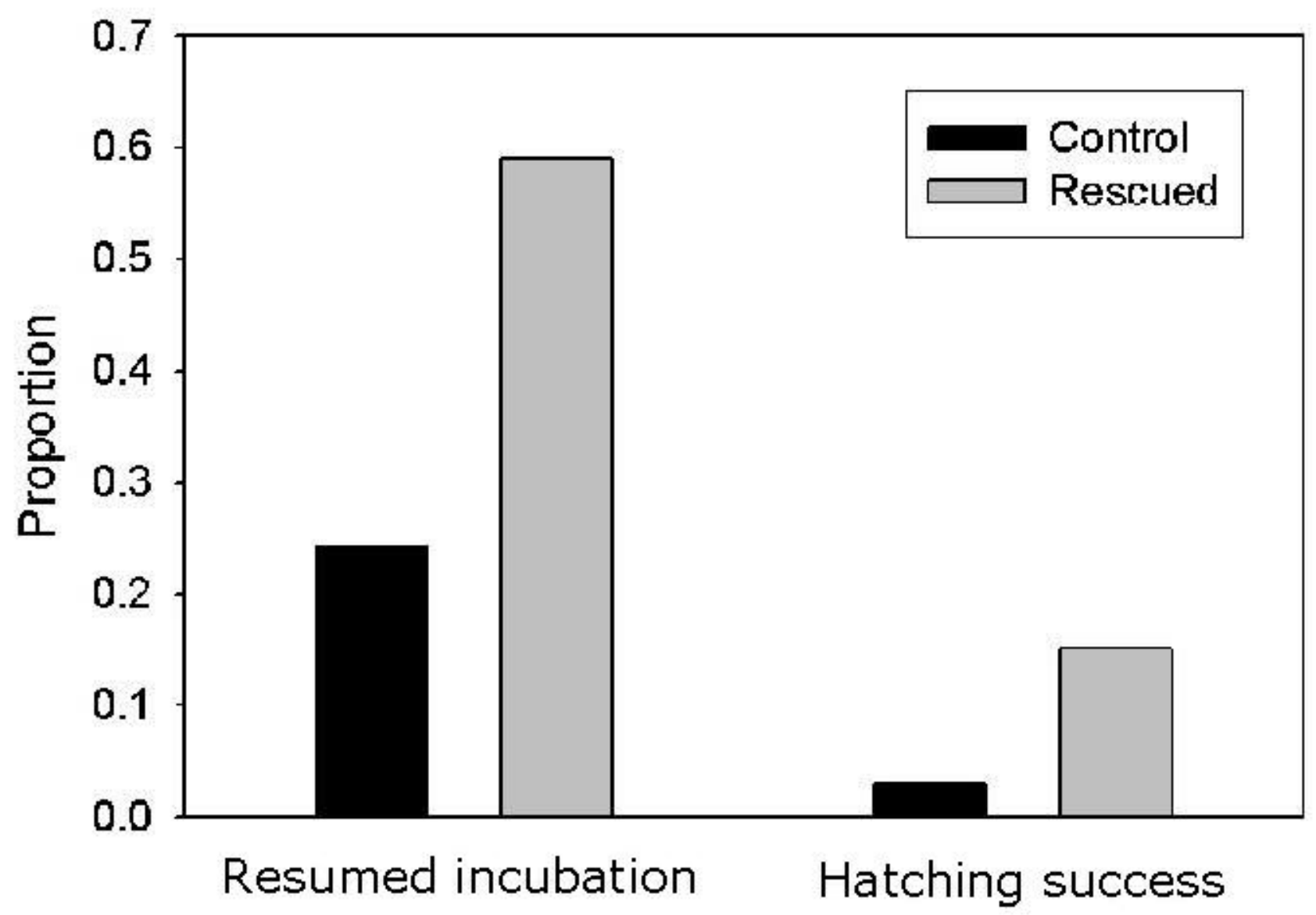

between coastal and inland areas predicted a tendency to move eggs, a suite of microhabitat variables beyond those measured here might contribute to differences between the two nesting sites, making the former preferable. Mosquito ectoparasitism has caused reproductive failure in the past (Anderson and Fortner 1988), and mosquito density increases inland (Anderson and Fortner 1988). Although mosquitoes were present in the 2002 season (J. A. Awkerman and K. P. Huyvaert, personal observation) and essentially absent during the other periods of this study, egg movement was common in all years. Moreover, Vásquez (1981) proposed and rejected the hypothesis that tick ectoparastism was positively correlated with frequent egg movement; both facts suggest that egg movement is unrelated to ectoparasitism.

Eggs in more inland areas tend to have lower hatch rates than eggs closer to the coast, so egg movement toward the coast might represent an adaptive adjustment to a poor choice of laying site. Egg movement may be the result of conflict in nest site selection among inexperienced pairs, because mates presumably move the egg toward a preferable nest site or between highly variable microhabitats. Adult 
birds typically begin returning to the colony at the age of $5 \mathrm{yr}$, lay later in a given season, and have a few unsuccessful breeding attempts before successfully breeding (Harris 1973). Although the creation of a nest scrape may allow young birds to begin early breeding attempts and gain experience in coordinating incubation stints before a final nesting territory has been established, egg narrowness, an indicator of experience, did not predict female movement frequency or hatching success in this study. Vásquez (1981) was also unable to identify differences in egg movement between birds older than $10 \mathrm{yr}$ and younger birds. A larger data set is needed before hypotheses regarding a bird's previous experience can be adequately tested in this species.

Egg rescue increases the likelihood of resuming incubation and hatching in situations in which egg movement results in the egg's becoming inaccessible. Hatching success in 2004 during the egg rescue experiment $(45.7 \%)$ is within the range (34.8-55.8\%) recorded by Harris (1973), and our estimates of adult survivorship for 1999-2002 are also close to his estimate of $95 \%$ (J. A. Awkerman, J. Mangel, J. A. Shigueto, K. P. Huyvaert, and D. J. Anderson, unpublished manuscript). In long-lived species with low fecundity, adult survivorship drives population dynamics, and annual reproductive success plays a less important role. In seeking management options to mitigate anthropogenic effects that compromise this life history strategy, increasing hatching success could have a minor influence compared to the effect of preserving the long life-span in the prevention of population decline (Crouse et al. 1987). If, by relocating lodged eggs, many inexperienced breeders have a successful breeding attempt earlier in their lifetimes than they would have had otherwise, egg rescue can directly increase breeding success within the birds' breeding habitat. This additional opportunity may not be enough to fully compensate for losses through fishery interactions and will require sustained human intervention, but it does provide an effective, low-cost management strategy for increasing reproductive success with minimal disturbance.

Responses to this article can be read online at: http://www.ace-eco.org/voll/iss 1/art2/responses/

\section{Acknowledgments:}

We thank the Galápagos National Park Service for permission to work in the Park; the Charles Darwin Research Station and TAME Airline for logistical support; the U.S. National Science Foundation (awards DEB 93045679, DEB 9629539, DEB 98-06606, and DEB 0235818 to DJA), the Swiss Friends of Galápagos, and the Wake Forest Environmental Studies Department (Biodiversity in Latin America Grant) for research funding; $M$. McCaustland, K. Tice, M. Westbrock, H. Reider, and E. Wakefield for field assistance; and $M$. McCaustland, the members of the Anderson lab group, and two anonymous reviewers for helpful comments on an earlier draft.

\section{LITERATURE CITED}

Anderson, D. J., and S. Fortner. 1988. Waved albatross egg neglect and associated mosquito ectoparasitism. Condor 90(3):727-729.

Anderson, D. J., K. P. Huyvaert, D. R. Wood, C. L. Gillikin, B. J. Frost, and H. Mouritsen. 2003. At-sea distribution of waved albatrosses and the Galapagos Marine Reserve. Biological Conservation 110:367-373.

Blomme, C. 1983. Egg-carrying behavior observed in Northern Flicker. Ontario Field Biologist 37:34-35.

Bolton, M., R. Medeiros, B. Hothersall, and A. Campos. 2004. The use of artificial breeding chambers as a conservation measure for cavitynesting procellariiform seabirds: a case study of the Madeiran storm petrel (Oceanodroma castro). Biological Conservation 116:73-80.

Brightsmith, D., J. Hilburn, A. del Campo, J. Boyd, M. Frisius, R. Frisius, D. Janik, and F. Guillen. 2005. The use of hand-raised psittacines for reintroduction: a case study of scarlet macaws (Ara macao) in Peru and Costa Rica. Biological Conservation 121:465-472.

Brown, C. R., and M. B. Brown. 1996. Coloniality in the Cliff Swallow. University of Chicago Press, 
Chicago, Illinois, USA.

Clifford, L. D., and D. J. Anderson. 2001. Food limitation explains most clutch size variation in the Nazca Booby. Journal of Animal Ecology 70: 539-545.

Crouse, D. T., L. B. Crowder, and H. Caswell. 1987. A stage-based population model for loggerhead sea turtles and implications for conservation. Ecology 68(5):1412-1423.

De Vries, T. 1984. The giant tortoises: a natural history disturbed by man. Pages 145-156 in R. Perry, editor. Key environments: Galápagos. Pergamon, New York, New York, USA.

Donald, P. F., A. D. Evans, L. B. Muirhead, D. L. Buckingham, W. B. Kirby, and S. J. A. Schmitt. 2002. Survival rates, causes of failure and productivity of skylark Alauda arvensis nests on lowland farmland. Ibis 144:652-664.

Gill, V. A., and S. A. Hatch. 2002. Components of productivity in black-legged kittiwakes Rissa tridactyla: response to supplemental feeding. Journal of Avian Biology 33:113-126.

Greenwood, P. J., and P. H. Harvey. 1982. The natal and breeding dispersal of birds. Annual Review of Ecology and Systematics 13:1-21.

Harris, M. P. 1973. The biology of the waved albatross Diomedea irrorata of Hood Island, Galápagos. Ibis 115(4):483-510.

Huyvaert, K. P. 2004. Social and genetic dynamics of extra-pair mating in waved albatrosses (Phoebastria irrorata). Dissertation. University of Missouri, St. Louis, Missouri, USA.

Kress, S. W., and D. N. Nettleship. 1988. Reestablishment of Atlantic Puffins (Fratercula arctica) at a former breeding site in the Gulf of Maine. Journal of Field Ornithology 59 (2):161-170.

Maicas, R., and J. F. Haeger. 2004. Pine plantations as a breeding habitat for a hole-nesting bird species crested tit (Parus cristatus) in southern Spain. Forest Ecology and Management 195:267-278.

Meretsky, V. J., N. F. R. Snyder, S. R. Beissinger, D. A. Clendenen, and J. W. Wiley. 2000.
Demography of the California condor: implications for reestablishment. Conservation Biology 14 (4):957-967.

Moorhouse, R., T. Greene, P. Dilks, R. Powlesland, L. Moran, G. Taylor, A. Jones, J. Knegtmans, D. Wills, M. Pryde, I. Fraser, A. August, and C. August. 2003. Control of introduced mammalian predators improves kaka Nestor meridionalis breeding success: reversing the decline of a threatened New Zealand parrot. Biological Conservation 110:33-44.

Rahbek, C. 1993. Captive breeding: a useful tool in the preservation of biodiversity? Biodiversity and Conservation 2:426-437.

Rechten, C. 1986. Factors determining the laying date of the waved albatrosses (Diomedea irrorata). Ibis 128(4):492-501.

Ryan, D. C., R. J. Carula, and R. J. Gates. 1998. Breeding biology of wood ducks using natural cavities in southern Illinois. Journal of Wildlife Management 62(1):112-123.

Stewart, P. A. 1974. A nesting of black vultures. The Auk 91:595-600.

Tickell, W. L. N. 2000. Albatrosses. Yale University Press, New Haven, Connecticut, USA.

Trost, C. H., and C. L. Webb. 1986. Egg moving behavior by two species of corvid. Animal Behavior 34:294-295.

Truslow, F. K. 1967. Egg-carrying by the pileated woodpecker. Living Bird 6:227-236.

Van Dyke, F., S. E. Van Kley, C. E. Page, and J. G. Van Beek. 2004. Restoration efforts for plant and bird communities in tallgrass prairies using prescribed burning and mowing. Restoration Ecology 12(4):575-585.

Vásquez, C. 1981. Why do waved albatrosses move their eggs? Charles Darwin Research Station, Puerto Ayora, Galápagos, Ecuador.

Weaver, H. B., and C. R. Brown. 2004. Brood parasitism and egg transfer in cave swallows (Petrochelidon fulva) and cliff swallows ( $P$. pyrrhonota) in South Texas. The Auk 121 (4):1122-1129. 
Zar, J. H. 1996. Biostatistical analysis. Prentice Hall, Upper Saddle River, New Jersey, USA. 